\title{
Polyphenols in lahpet-so and two new catechin metabolites produced by anaerobic microbial fermentation of green tea
}

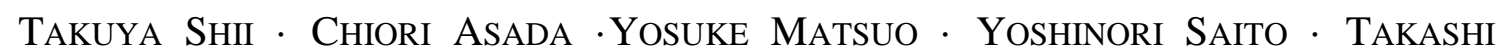

TANAKA*

T. Shii $\cdot$ C. Asada $\cdot$ Y. Matsuo $\cdot$ Y. Saito $\cdot$ T. Tanaka*

Graduate School of Biomedical Sciences, Nagasaki University, Bunkyo-Machi 1-14, Nagasaki 852-8521, Japan

E-mail: t-tanaka@nagasaki-u.ac.jp

Tel.: +81-95-819-2433

Fax: +81-95-819-2477 
Abstract The phenolic constituents of lahpet-so, a traditional postfermented tea of Myanmar produced under anaerobic conditions, were examined. The major polyphenols were identified to be pyrogallol and 4'-hydroxyphenyl-3-(2",4",6"--trihydroxyphenyl)-propan-2-ol, 3',4'-dihydroxyphenyl-3-(2",4",6"-trihydroxyphenyl)-propan-2-ol, and 3',4',5'-trihydroxyphenyl-3-(2",4",6"-trihydroxyphenyl)-propan-2-ol. The hydroxydiphenylpropan-2-ols were identical to the initial metabolites produced from green tea catechins by mammalian intestinal bacteria. In addition, an anaerobic mixed-fermentation experiment using lahpet-so and Japanese commercial green tea afforded two new catechin degradation products together with known compound bruguierol B and the above-mentioned catechin metabolites. Based on spectroscopic evidence, the structures of the new compounds were concluded to be 4-(2,5-dihydroxyhexyl)benzene-1,2-diol and (5S,8R)-6,7,8,9-tetrahydro-5-methyl-5,8-epoxy-5H-benzocycloheptene-2,3,4-triol. Interestingly, the production mechanism was deduced to be the inverse of the biosynthesis of the flavan-3-ol A ring.

Keywords Lahpet-so - Catechin · Anaerobic fermentation · Tea · Polyphenol · Intestinal metabolism 


\section{Introduction}

Based on epidemiological and biological studies conducted since the 1980s, the various health benefits of green tea catechins have become well recognized [1-3]. However, the bioavailability of tea catechins from the digestive tract is low $[4,5]$. Therefore, it has been suggested that catechin degradation products generated by intestinal bacteria are important in the biological activity of green tea [6-8]. Recently, we reported that Japanese postfermented tea produced by anaerobic microbial fermentation of green tea contained polyphenols identical to the tea catechin metabolites formed by mammalian intestinal bacteria [9]. We also demonstrated that the same metabolism was able to be reproduced by in vitro anaerobic treatment of pure tea catechin with microorganisms that remained in the postfermented tea [10].

In the present study, the polyphenols in lahpet-so, a traditional fermented tea of Myanmar, were investigated. Lahpet-so is a pickled tea that is produced by anaerobic fermentation of green tea, and its production process is similar to that used for Japanese postfermented tea, such as awa bancha and goishicha, produced in the Shikoku region of Japan [9]. In addition, microbial degradation of tea catechins was also examined in a mixed-fermentation experiment of green tea with commercial lahpet-so.

\section{Results and discussion}

Comparison of green tea and commercial lahpet-so (Fig. 1) by high-performance liquid chromatography (HPLC) revealed the absence of four major tea catechins, (-)-epigallocatechin (1), (-)-epicatechin (2), and their 3-O-galloyl esters, in lahpet-so. 
The major constituents detected in lahpet-so were isolated by a combination of column chromatography using Sephadex LH-20, MCI-gel CHP20P, and Chromatorex ODS, and were $\quad$ identified as $\quad$ pyrogallol

(2S)-1-(3',4',5'-trihydroxyphenyl)-3-(2",4",6"-trihydroxyphenyl)-propan-2-ol

(2S)-1-(3',4'-dihydroxyphenyl)-3-(2",4",6"-trihydroxyphenyl)-propan-2-ol

(5), and

(2S)-1-(4'-hydroxyphenyl)-3-(2",4",6"-trihydroxyphenyl)-propan-2-ol

(6) (Fig. 2).

Compounds 4-6 were reported to be metabolites of catechins and proanthocyanidins produced by mammalian intestinal bacteria $[6,7,11,12]$. Pyrogallol $(3)$ is considered to be produced by degradation of gallic acid $[9,10]$, while the three diphenylpropane derivatives are reduction products of 2, 3, and (-)-epiafzelechin. Compound 6 has been identified only by liquid chromatography/mass spectrometry and was first isolated in this study. This metabolite may be produced from 5 , because removal of the oxygen atom was sometimes observed in the anaerobic microbial metabolism of polyphenols [6]. The results revealed that the degradation of tea catechins during the production of lahpet-so is similar to that observed in the production of Japanese anaerobic postfermented tea products such as awa bancha (Tokushima Prefecture), goishicha (Kochi Prefecture), and ishizuchi-kurocha (Ehime Prefecture) [9].

Next, we examined anaerobic mixed-fermentation of lahpet-so with Japanese green tea. Green tea was swollen in water and mixed with commercial lahpet-so and kept under anaerobic conditions at $37{ }^{\circ} \mathrm{C}$. After 6 weeks, HPLC analysis indicated production of compounds $\mathbf{3} \mathbf{- 5}$, and after 10 weeks, two uncharacterized peaks owing to compounds 7-9 became apparent (Fig. 3). These metabolites were separated by repeated column chromatography, and comparison of physical and spectroscopic data 
identified compound $\mathbf{9}$ as bruguierol B, which had been isolated from Bruguiera gymnorrhiza (Rhizophoraceae) [13].

New compound 7 was obtained as a brown amorphous powder, and the molecular formula was found to be $\mathrm{C}_{12} \mathrm{H}_{18} \mathrm{O}_{4}$ by HR-ESI-TOF MS. The ${ }^{1} \mathrm{H}$ nuclear magnetic resonance $(\mathrm{NMR})$ spectrum showed three aromatic protons $[\delta 6.66(1 \mathrm{H}, \mathrm{d}, J=$ $\left.\left.8.0 \mathrm{~Hz}, \mathrm{H}-5^{\prime}\right), 6.64\left(1 \mathrm{H}, \mathrm{d}, J=2.1 \mathrm{~Hz}, \mathrm{H}-2^{\prime}\right), 6.51\left(1 \mathrm{H}, \mathrm{dd}, J=8.0,2.1 \mathrm{~Hz}, \mathrm{H}-6^{\prime}\right)\right]$, and the coupling pattern indicated a 1,3,4-trisubstituted benzene ring. This benzene ring was shown to be a catechol ring by the appearance of dark-green coloration with $\mathrm{FeCl}_{3}$ reagent on thin-layer chromatography (TLC) [Rf 0.64; toluene/ethyl formate/formic acid (1:7:1)] and the appearance of six aromatic carbons at $\delta 146.0$ (C-3'), 144.6 (C-4'), 132.0 (C-1'), 121.7 (C-6’), 117.6 (C-2'), and 116.2 (C-5') in the ${ }^{13} \mathrm{C}^{\prime} \mathrm{NMR}$ spectrum. The remaining part of the molecule contained six aliphatic carbons: two oxygenated methine carbons [ $\delta 74.1(\mathrm{C}-2), 68.8(\mathrm{C}-5)]$, three methylene carbons [ $\delta 44.5(\mathrm{C}-1), 36.4$ (C-4), 33.8 (C-3)], and a methyl carbon [ $\delta 23.5$ (C-6)]. The ${ }^{1} \mathrm{H}-{ }^{1} \mathrm{H}$ COSY spectrum confirmed that these carbons make up a 2,5-dihydroxyhexyl group, and thus, 7 was identified as 4-(2,5-dihydroxyhexyl)benzene-1,2-diol (Fig. 4). This assignment was supported by long-range ${ }^{1} \mathrm{H}-{ }^{1} \mathrm{H}$ coupling between aromatic proton $\mathrm{H}-2$ ' and the benzylic methylene proton $[\mathrm{H}-1, \delta 2.61(1 \mathrm{H}, \mathrm{dd}, J=13.5,6.9 \mathrm{~Hz}), 2.55(1 \mathrm{H}, \mathrm{dd}, J=13.5,6.4$ Hz)]. In addition, correlations of $\mathrm{H}-1$ to $\mathrm{C}-1$ ', C-2', and C-6' observed in the HMBC spectrum confirmed the structure. This metabolite is apparently produced from 2; therefore, the stereostructure at $\mathrm{C}-2$ was deduced to be the $R$ configuration. The configuration at the C-5 methine carbon could not be determined in this study.

Compound 8 was isolated as brown amorphous powder, and the molecular formula was found to be $\mathrm{C}_{12} \mathrm{H}_{14} \mathrm{O}_{4}$ by HR-ESI-MS (m/z: $245.0761[\mathrm{M}+\mathrm{Na}]^{+}$, calcd. for 
$\mathrm{C}_{12} \mathrm{H}_{14} \mathrm{O}_{4} \mathrm{Na}$, 245.0790). The ${ }^{13} \mathrm{C}$ NMR spectrum showed six aromatic carbon signals attributable to a pyrogallol ring [ $\delta 145.7$ (C-5'), 143.7 (C-3'), 132.0 (C-4'), 124.8 (C-1'), 122.4 (C-2'), $\left.108.2\left(\mathrm{C}-6^{\prime}\right)\right]$ and six aliphatic carbon signals including an oxygenated quaternary carbon [ $\delta 82.2(\mathrm{C}-5)]$, an oxygenated methine $[\delta 75.3(\mathrm{C}-2)]$, three

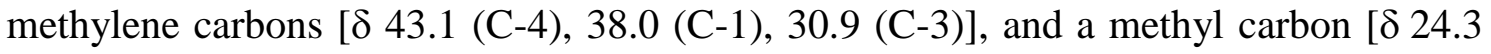
(C-6)]. The ${ }^{1} \mathrm{H}-{ }^{1} \mathrm{H}$ COSY correlations revealed the proximity of three methylenes (C-1, C-3, and C-4) and an oxygenated methine (C-2) (Fig. 4). In the HMBC spectrum, the aromatic singlet at $\delta 6.07\left(\mathrm{H}-6^{\prime}\right)$ showed correlations with an aromatic quaternary carbon (C-2') and a benzylic methylene carbon (C-1). The benzylic methylene proton correlated to aromatic carbons (C-1', C-2', and C-6'). Furthermore, the methyl group singlet H-6 ( $\delta 1.83)$ showed correlations with C-5 and C-2'. These correlations suggested that 8 has a benzocycloheptane skeleton. The unsaturation index of 6 and the chemical shift of the aliphatic quaternary carbon [ $\delta 82.2$ (C-5)] indicated an ether linkage between two oxygenated aliphatic carbons, that is, C-2 and C-5. This was also confirmed by the HMBC correlation from H-2 to C-5. Thus, the structure of $\mathbf{8}$ was assigned as shown in Fig. 2 [systematic name: (5S,8R)-6,7,8,9-tetrahydro-5-methyl-5,8-epoxy-5H-benzocycloheptene-2,3,4-triol]. This product is presumed to be a degradation product of $\mathbf{1}$; thus, the configurations of the C-2 and C-5 carbons were deduced to be $R$ and $S$, respectively.

Mechanisms for the production of $\mathbf{7}$ and $\mathbf{8}$ were proposed as shown in Fig. 5. Bruguierol B (9) was also deduced to be one of the metabolites of 2 . In the mechanism, degradation of the phloroglucinol ring is the inverse of the biosynthesis of the flavan-3-ol A ring, and it is closely related to the production metabolism of hydroxyphenyl-4-hydroxypentanoic acids $\quad(\mathbf{1 0}$ and $\mathbf{1 1})$ and 
hydroxyphenyl- $\gamma$-valerolactones (12 and 13), which are major catechin metabolites produced by mammalian intestinal bacteria [6-8] and were not detected in this experiment. The metabolites $\mathbf{1 2}$ and $\mathbf{1 3}$ are produced by removal of 2 acetic acid units from 4 and 5 via intermediates $\mathbf{4 a , b}$ and $\mathbf{5 a , b}$. In contrast, our results indicated that the microorganisms of lahpet-so lack the enzyme catalyzing the second elimination of the acetic acid unit from $\mathbf{4} \mathbf{b}$ and $\mathbf{5 b}$. Instead, the intermediates undergo decarboxylation to generate 1-phenyl-2-hydroxyhexan-5-one intermediates $\mathbf{4 c}$ and $\mathbf{5 c}$. Subsequent reduction of the carbonyl group of 5c generates 7 . In addition, intramolecular 1,2-addition of aromatic carbon to the carbonyl groups of $\mathbf{4 c}$ and $\mathbf{5 c}$ gives diol-intermediates $\mathbf{8 a}$ and $\mathbf{9 a}$, which are converted to $\mathbf{8}$ and $\mathbf{9}$, respectively, by intramolecular dehydration. Although the products obtained in our experiment were different from metabolites of intestinal bacteria, the initial reductive cleavage of flavan C-ring and subsequent elimination of an acetic acid unit commonly occur [6], and particularly, accumulation of the common metabolites $\mathbf{4}$ and $\mathbf{5}$ in anaerobic postfermentation is important for the biological activities of tea catechins.

\section{Experimental}

\section{General}

Ultraviolet (UV) spectra were obtained with a Jasco V-560 UV/VIS spectrophotometer, while CD spectra were measured with a Jasco J-725N spectrophotometer. ${ }^{1} \mathrm{H}$ and ${ }^{13} \mathrm{C}$ NMR spectra were recorded in acetone- $d_{6}$ with a Varian Unity Plus 500 spectrometer operating at $500 \mathrm{MHz}$ for ${ }^{1} \mathrm{H}$ and $125 \mathrm{MHz}$ for ${ }^{13} \mathrm{C}$ and with a JEOL JNM-AL 400 
spectrometer operating at $400 \mathrm{MHz}$ for ${ }^{1} \mathrm{H}$ and $100 \mathrm{MHz}$ for ${ }^{13} \mathrm{C}$. HR-ESI-MS spectra were obtained using a JEOL JMS-T100TD spectrometer (JEOL, Tokyo, Japan). HR-FAB-MS were recorded on a JMS 700N spectrometer (JEOL), with m-nitrobenzyl alcohol or glycerol as the matrix. Column chromatography was performed using Sephadex LH-20 (25-100 mm, GE Healthcare, Little Chalfont, UK), MCI-gel CHP 20P (75-150 mm, Mitsubishi Chemical, Tokyo, Japan), Diaion HP20SS (Mitsubishi Chemical), Chromatorex ODS (Fuji Silysia Chemical, Kasugai, Japan), and Bondapak $\mathrm{C}_{18}$ 125A (Waters, Milford, MA, USA). TLC was performed on precoated Kieselgel 60 $\mathrm{F}_{254}$ plates $(0.2 \mathrm{~mm}$ thick, Merck) with toluene/ethyl formate/formic acid (1:7:1, v/v) and $\mathrm{CHCl}_{3} / \mathrm{MeOH} / \mathrm{H}_{2} \mathrm{O}(7: 3: 0.5, \mathrm{v} / \mathrm{v})$. Spots were detected using UV illumination and by spraying with $2 \%$ ethanolic $\mathrm{FeCl}_{3}$ or $5 \% \mathrm{H}_{2} \mathrm{SO}_{4}$ reagent followed by heating. Analytical HPLC was performed on a Cosmosil 5C 18 -AR II (Nacalai Tesque) column (250 × $4.6 \mathrm{~mm}$ i.d.) with gradient elution from 4-30\% (39 min) and 30-75\% (15 min) of $\mathrm{CH}_{3} \mathrm{CN}$ in $50 \mathrm{mM} \mathrm{H} \mathrm{H}_{3} \mathrm{PO}_{4}$ at $35{ }^{\circ} \mathrm{C}$ (flow rate, $0.8 \mathrm{ml} / \mathrm{min}$; detection, Jasco photodiode array detector MD-910).

\section{Plant material}

Commercial lahpet-so, fermented tea packed with food oil imported from Myanmar, was purchased at a local market in Tokyo. Green tea was supplied by Nagasaki Prefectural Agricultural and Forestry Experiment Station, Higashisonogi Tea Branch. 


\section{Extraction and isolation}

Lahpet-so (112 g) was successively extracted with acetone (200 mL, for 2 days) and acetone $/ \mathrm{H}_{2} \mathrm{O}$ (7:3, v/v, $200 \mathrm{~mL}$, for 1 day). The extracts were combined and concentrated by rotary evaporation under reduced pressure $\left(c a .40^{\circ} \mathrm{C}\right)$. The resulting mixture was suspended in $\mathrm{H}_{2} \mathrm{O}$ (200 mL) and successively partitioned with hexane (200 $\mathrm{mL}$, three times) and $\mathrm{CHCl}_{3}$ (200 mL, twice) to give hexane extract (14.5 g) and a $\mathrm{CHCl}_{3}$ fraction $(3.1 \mathrm{~g})$. The hexane and $\mathrm{CHCl}_{3}$ fractions mainly contained food oil and caffeine, respectively. The $\mathrm{H}_{2} \mathrm{O}$ fraction (9.6 g) was subjected to Sephadex LH-20 column chromatography $(4 \mathrm{~cm}$ i.d. $\times 30 \mathrm{~cm}$ ) with water containing increasing proportions of methanol (120\% stepwise elution from 0 to $100 \%)$ and finally with 50 \% aqueous acetone, and fractionated into nine fractions: 1 (5.7 g), 2 (469 mg), 3 (598 mg), 4 (97 mg), 5 (73 mg), 6 (942 mg), 7 (260 mg), 8 (385 mg), and 9 (120 mg). The first fraction mainly contained sugars. Fractions 1 and 2 contained sugars and organic acids. Fraction 3 was identified as pyrogallol (3) by TLC with the authentic sample [Rf 0.84; toluene/ethyl formate/formic acid (1:7:1)] and by ${ }^{1} \mathrm{H}$ NMR comparison. Fraction 6 was mainly composed of $\mathrm{FeCl}_{3}$-positive compounds and was separated into three fractions by MCI-gel CHP20P (0-100 \% methanol in $\mathrm{H}_{2} \mathrm{O}, 10 \%$ stepwise elution). $\begin{array}{llllll}\text { Subfraction } & 6-1 & (405.5 & \mathrm{mg}) & \text { was } & \text { identified }\end{array}$ (2S)-1-(3',4',5'-trihydroxyphenyl)-3-(2",4",6"-trihydroxyphenyl)-propan-2-ol

Subfraction 6-2 (290 mg) was applied to a Chromatorex ODS column (2 cm i.d. $\times 20$ $\mathrm{cm}$ ) and eluted with 0-100 \% methanol in $\mathrm{H}_{2} \mathrm{O}$ to give fractions 6-2-1 (11 mg), 6-2-2 (240 mg), and (-)-epicatechin (2) (16.1 mg). Fraction 6-2-2 was subjected to Sephadex LH-20 column chromatography (2 cm i.d. $\times 20 \mathrm{~cm}$ ) with $0-100 \%$ methanol in $\mathrm{H}_{2} \mathrm{O}$ to yield (2S)-1-(3',4'-dihydroxyphenyl)-3-(2",4",6"-trihydroxyphenyl)-propan-2-ol 
(216.9 mg). Subfraction 6-3 (73.2 mg) was separated by Chromatorex ODS column chromatography (2 cm i.d. $\times 20 \mathrm{~cm}, 0-100 \%$ methanol in $\left.\mathrm{H}_{2} \mathrm{O}\right)$ to give (2S)-1-(4'-hydroxyphenyl)-3-(2",4",6"-trihydroxyphenyl)-propan-2-ol (6) (12.4 mg) and (-)-epiafzelechin (6.8 mg).

\section{1-(4'-Hydroxyphenyl)-3-(2",4",6"-trihydroxyphenyl)-propan-2-ol (6)}

A brown amorphous powder; $[\alpha]_{\mathrm{D}}-12.0^{\circ}$ (c 0.1, methanol). ESI-MS: m/z $277[\mathrm{M}+\mathrm{H}]^{+}$. HR-FAB-MS: m/z 277.1096 [M+H] $]^{+}$(calcd. for $\mathrm{C}_{15} \mathrm{H}_{17} \mathrm{O}_{5}, 277.1076$ ). IR $v_{\max } \mathrm{cm}^{-1}$ : 3409, 2923, 1633, 1517, 1457, 1248, 1153, 1075. UV $\lambda_{\max }$ (methanol) nm (log $\varepsilon$ ): 207

(3.11), 226 (3.39), 276 (4.14). ${ }^{1} \mathrm{H}$ NMR (400 MHz, CD $\left.{ }_{3} \mathrm{OD}\right) \delta: 2.55$ (1H, dd, $J=8.4$,

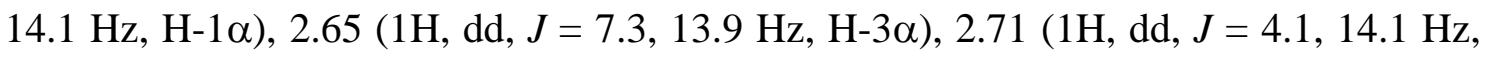

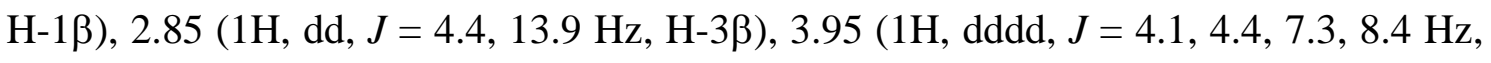
H-2), 5.87 (2H, s, H-3", 5"), 6.67 (2H, d, $J=8.6$ Hz, H-3', 5'), 7.02 (2H, d, $J=8.6$ Hz, H-2', 6'). ${ }^{13} \mathrm{C}$ NMR (100 MHz, CD $\left.{ }_{3} \mathrm{OD}\right)$ 8: 31.5 (C-3), 43.5 (C-1), 75.4 (C-2), 95.9 (C-3", 5"), 105.7 (C-1"), 115.9 (C-3', 5'), 131.4 (C-2', 6'), 131.8 (C-1'), 156.5 (C-4'), 157.7 (C-4"), 158.2 (C-2", 6").

\section{Mixed fermentation of green tea and lahpet-so}

Green tea (200 g) was mixed with $\mathrm{H}_{2} \mathrm{O}(1.2 \mathrm{l})$ and heated in a microwave oven (600 W) for $3 \mathrm{~min}$. After cooling $\left(40^{\circ} \mathrm{C}\right)$, commercial lahpet-so (10 g) was mixed with the wet green tea and tightly packed into a bottle with a stopper. After fitting the stopper, the bottle was kept at $37{ }^{\circ} \mathrm{C}$ for 10 weeks. The fermented tea $(800 \mathrm{~g})$ was extracted with acetone $/ \mathrm{H}_{2} \mathrm{O}$ (3:2, $\left.1 \mathrm{l}\right)$ three times, and the extract was concentrated under reduced 
pressure. After removal of insoluble material formed in the resulting aqueous solution (600 mL) by filtration, the filtrate was partitioned with ethyl acetate $(600 \mathrm{~mL}$, three times) to give an ethyl acetate fraction (23.1 g). This fraction was fractionated by Diaion HP20SS column chromatography $\left(7.5 \mathrm{~cm}\right.$ i.d. $\times 30 \mathrm{~cm}, 0-100 \%$ methanol in $\left.\mathrm{H}_{2} \mathrm{O}\right)$ into eight fractions: 1 (0.5 g), 2 (7.0 g), 3 (4.3 g), 4 (3.0 g), 5 (2.1 g), 6 (2.9 g), 7 (0.21 g), and 8 (2.8 g). HPLC analysis of the fractions indicated that fraction 2 contained 3, 4, and 1. Fraction 3 (4.3 g) was mainly composed of 2, 5, and epigallocatechin-3-O-gallate. This fraction was separated by column chromatography on Diaion HP20SS ( $3 \mathrm{~cm}$ i.d. $\times 25 \mathrm{~cm}, 0-100 \%$ methanol in $\mathrm{H}_{2} \mathrm{O}$ ) to give seven subfractions. Subfraction 3-5 (1.8 g) was applied to a Sephadex LH-20 column (2.5 cm i.d. $\times 20 \mathrm{~cm}$ ) with ethanol and the first fraction $(31.9 \mathrm{mg})$ was then passed through a Bondapak $\mathrm{C}_{18} 125 \mathrm{~A}$ column $\left(1.0 \mathrm{~cm}\right.$ i.d. $\left.\times 10 \mathrm{~cm}, 0-40 \% \mathrm{CH}_{3} \mathrm{CN}\right)$ to give $7(7.4 \mathrm{mg})$. Fraction 4 contained epicatechin-3-O-gallate and caffeine. Fraction 5 of the ethyl acetate fraction was separated by silica gel column chromatography $(4 \mathrm{~cm}$ i.d. $\times 20 \mathrm{~cm})$ with $\mathrm{CHCl}_{3} /$ methanol/ $\mathrm{H}_{2} \mathrm{O}(90: 10: 1,80: 20: 2$, and then $70: 30: 5)$, and the first fraction (fraction 5-1, $439 \mathrm{mg}$ ) was purified by successive column chromatography with Chromatorex ODS (2 cm i.d. $\times 18 \mathrm{~cm}, 0-60 \%$ methanol in $\left.\mathrm{H}_{2} \mathrm{O}\right)$ and silica gel $(3 \mathrm{~cm}$ i.d. $\times 20 \mathrm{~cm}, \mathrm{CHCl}_{3} / \mathrm{methanol} \mathrm{H}_{2} \mathrm{O}$ 90:10:1 and then 80:20:2) to yield compound 8 (103 mg). Fraction 6 was subjected to silica gel column chromatography $(3 \mathrm{~cm}$ i.d. $\times 20 \mathrm{~cm}$, $\mathrm{CHCl}_{3} /$ methanol/ $\mathrm{H}_{2} \mathrm{O}$ 90:10:1 and then 85:15:1) to give bruguierol B (9) (120 mg). 


\section{Compound 7}

Brown amorphous powder; $[\alpha]_{\mathrm{D}}-4.1^{\circ}$ (c 0.10 , methanol). ESI-TOF-MS: m/z 249 $[\mathrm{M}+\mathrm{Na}]^{+}$. HR-ESI-MS: m/z 249.1093 [M+Na] ${ }^{+}$(calcd. for $\mathrm{C}_{12} \mathrm{H}_{18} \mathrm{O}_{4} \mathrm{Na}, 249.1103$ ). UV

$\lambda_{\max }{ }^{\mathrm{MeOH}} \mathrm{nm}(\log \varepsilon): 220$ (3.88), 282 (3.49). IR $v_{\max } \mathrm{cm}^{-1}$ : 3266, 2966, 2928, 1604, 1556, 1520, 1446. ${ }^{1} \mathrm{H}$ NMR (500 MHz, CD $\mathrm{CDD}_{3}$ ) 6.66 (1H, d, $J=8.0 \mathrm{~Hz}, \mathrm{H}-5$ '), 6.64 (1H, d, $J=2.1 \mathrm{~Hz}, \mathrm{H}-2$ '), 6.51 (1H, dd, $J=8.0,2.1 \mathrm{~Hz}, \mathrm{H}-6$ '), 3.68 (2H, m, H-2, 5), 2.61 (1H, dd, $J=13.5,6.9 \mathrm{~Hz}, \mathrm{H}-1), 2.55$ (1H, dd, $J=13.5,6.4 \mathrm{~Hz}, \mathrm{H}-1), 1.61$ (2H, m, H-3, 4), 1.43 (1H, m, H-4), 1.33 (1H, br dd, $J=18.8,8.3 \mathrm{~Hz}, \mathrm{H}-3), 1.12$ (3H, d, $J=6.2 \mathrm{~Hz}$, H-6). ${ }^{13} \mathrm{C}$ NMR (125 MHz, CD $\left.{ }_{3} \mathrm{OD}\right)$ \&: 146.0 (C-3'), 144.6 (C-4'), 132.0 (C-1'), 121.7 (C-6'), 117.6 (C-2'), 116.2 (C-5'), 74.1 (C-2), 68.8 (C-5), 44.5 (C-1), 36.4 (C-4), 33.8 (C-3), 23.5 (C-6).

\section{Compound 8}

Brown amorphous powder; $[\alpha]^{23} \mathrm{D}+9.5^{\circ}$ (c 0.1 , methanol). UV (methanol) $\lambda_{\max }(\log \varepsilon)$ : 272 (3.29), 211 (4.77), 207 (4.77). IR $v_{\max } \mathrm{cm}^{-1}$ : 3422, 1653, 1507. FAB-MS (matrix glycerol + NaCl): m/z $223[\mathrm{M}+\mathrm{H}]^{+}, 207\left[\mathrm{M}-\mathrm{CH}_{3}\right]^{+}$. HR-ESI-MS: m/z 245.0761 (calcd. for $\mathrm{C}_{12} \mathrm{H}_{14} \mathrm{O}_{4} \mathrm{Na}$, 245.0790). ${ }^{1} \mathrm{H}$ NMR (400 MHz, $\left.\mathrm{CD}_{3} \mathrm{OD}\right) \delta: 6.07$ (1H, s, H-6'), 4.57 (1H, m, H-2), 3.15 (1H, dd, $J=5,16 \mathrm{~Hz}, \mathrm{H}-1), 2.28$ (1H, d, $J=16 \mathrm{~Hz}, \mathrm{H}-1), 2.17(1 \mathrm{H}$, m, H-3), 2.10 (1H, m, H-4), 1.83 (3H, s, H-6) 1.71 (1H, m, H-4), 1.59 (1H, m, H-3). ${ }^{13} \mathrm{C}$ NMR (100 MHz, CD $\left.{ }_{3} \mathrm{OD}\right)$ 8: 145.7 (C-5'), 143.7 (C-3'), 132.0 (C-4'), 124.8 (C-1'), 122.4 (C-2'), 108.2 (C-6'), 82.2 (C-5), 75.3 (C-2), 43.1 (C-4), 38.0 (C-1), 30.9 (C-3), $24.3(\mathrm{C}-6)$. 


\section{Bruguierol B (9)}

Yellow amorphous powder; $[\alpha]^{24}{ }_{D}+17.1^{\circ}$ (c 0.1, methanol). UV (methanol) $\lambda_{\max }(\log \varepsilon)$ : 287 (3.94), 209 (4.51), 206 (4.49). IR $v_{\max } \mathrm{cm}^{-1}$ : 3140, 1700, 1605, 1600, 1539. FAB-MS (positive): m/z $207[\mathrm{M}+\mathrm{H}]^{+}$. HR-FAB-MS: m/z 207.1021 [M+H] $]^{+}$(calcd. for $\mathrm{C}_{12} \mathrm{H}_{15} \mathrm{O}_{3}, 207.1021$ ). ${ }^{1} \mathrm{H}$ NMR (400 MHz, acetone- $d_{6}+\mathrm{D}_{2} \mathrm{O}$ ) $\delta:$ 7.65, 7.54 (each $1 \mathrm{H}$, br s, 4, 5-OH) 6.64 (1H, s, H-3'), 6.50 (1H, s, H-6'), 4.57 (1H, m, H-2), 3.08 (1H, dd, $J=$ 5, $16 \mathrm{~Hz}, \mathrm{H}-1), 2.31$ (1H, d, $J=16$ Hz, H-1), 2.12 (1H, m, H-3), 1.90 (1H, m, H-4), 1.71 (1H, m, H-4), 1.62 (1H, m, H-3) 1.56 (1H, s, H-6). ${ }^{13} \mathrm{C}$ NMR (100 MHz, acetone- $d_{6}+$ D $\left.{ }_{2} \mathrm{O}\right)$ 8: 144.5 (C-5'), 143.8 (C-4'), 136.6 (C-2'), 123.8 (C-1'), 116.5 (C-6'), 120.8 (C-3'), 80.4 (C-5), 74.8 (C-2), 43.7 (C-4), 37.4 (C-1), 31.0 (C-3), 23.2 (C-6).

\section{Acknowledgments}

The authors are grateful to Mr. K. Inada and Mr. N. Tsuda (Nagasaki University) for NMR and MS measurements, and to Dr. Y. Miyata, Nagasaki Prefectural Agricultural and Forestry Experiment Station, Higashisonogi Tea Branch, for supplying green tea.

\section{References}

1. Ho CT, Lin JK, Shahidi F (2008) Tea and tea products: chemistry and health-promoting properties. CRC Press, Boca Raton, FL

2. Hara Y (2001) Green tea: health benefits and applications. Taylor and Francis, Boca Raton, FL 
3. Juneja LR, Kapoor MP, Okubo T, Rao TP (2013) Green tea polyphenols: nutraceuticals of modern life, CRC Press, Boca Raton, FL

4. Miyazawa $\mathrm{T}$ (2000) Absorption, metabolism and antioxidative effects of tea catechin in humans. BioFactors 13:55-59

5. Zhu M, Chen Y, Li RC (2000) Oral absorption and bioavailability of tea catechins. Planta Medica 66:444-447

6. Takagaki A, Nanjo F (2010) Metabolism of (-)-epigallocatechin gallate by rat intestinal flora. J Agric Food Chem 58:1313-1321

7. Wang LQ, Meselhy MR, Li Y, Nakamura N, Min BS, Qin GW, Hattori M (2001) The heterocyclic ring fission and dehydroxylation of catechins and related compounds by Eubacterium sp. Strain SDG-2, a human intestinal bacterium. Chem Pharm Bull 49:1640-1643

8. Jin JS, Hattori M (2012) Isolation and characterization of a human intestinal bacterium eggerthella sp. CAT-1 capable of cleaving the C-ring of (+)-catechin and (-)-epicatechin, followed by p-dehydroxylation of the B-ring. Biol Pharm Bull $35: 2252-2256$

9. Tanaka T, Nagai S, Shii T, Matsuo Y, Kouno I (2011) Isolation of 1,3-diphenylpropan-2-ols, identical to tea catechin metabolites produced by intestinal bacteria, and pyrogallol from Japanese post-fermented tea. Nippon Shokuhin Kagaku Gakkaishi 18:6-11

10. Tanaka T, Umeki H, Nagai S, Shii T, Matsuo Y, Kouno I (2012) Transformation of tea catechins and flavonoid glycosides by treatment with Japanese post-fermented tea acetone powder. Food Chem 134:276-281 
11. Stoupi S, Williamson G, Drynan JW, Barron D, Clifford MN (2010) A comparison of the in vitro biotransformation of (-)-epicatechin and procyanidin B2 by human faecal microbiota. Mol Nutr Food Res 54:747-759

12. Meselhy MR, Nakamura N, Hattori M (1997) Biotransformation of (-)-epicatechin 3-O-gallate by human intestinal bacteria title. Chem Pharm Bull 45:888-893

13. Han L, Huang X, Sattler I, Moellmann U, Fu H, Lin W, Grabley S (2005) New aromatic compounds from the marine mangrove Bruguiera gymnorrhiza. Planta Medica 71:160-164 
Figure Legends

Fig. 1 HPLC profiles of green tea (A) and lahpet-so (B) (maximum absorbance).

GA, gallic acid; TG, theogallin; GC, gallocatechin; 1, epigallocatechin; Caf, caffeine; 2, epicatechin; EGCg, epigallocatechin-3-O-gallate; GCg, gallocatechin-3-O-gallate; ECg, epicatechin-3-O-gallate

Fig. 2 Structures of compounds 1-9

Fig. 3 HPLC (maximum absorbance) of mixed-fermentation product of green tea with lahpet-so (after 10 weeks)

Fig. $4{ }^{1} \mathrm{H}-{ }^{1} \mathrm{H}$ COSY and HMBC correlations for $\mathbf{7}$ and $\mathbf{8}$

Fig. 5 Possible production mechanism for $\mathbf{7}$ and $\mathbf{8}$ 

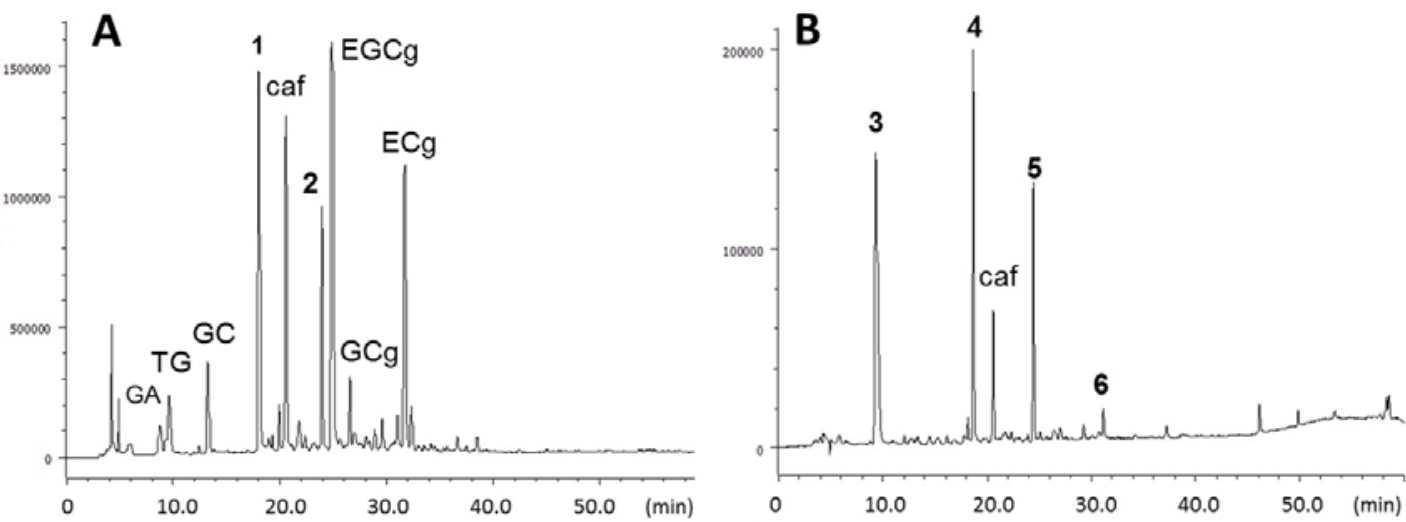

Fig. 1 HPLC profile of green tea (A) and lahpet-so (B) (max absorbance).

GA: gallic acid, TG: theogallin, GC: gallocatechin, 1: epigallocatechin, Caf: caffeine, 2: epicatechin, EGCg: epigallocatechin-3-O-gallate, GCg: gallocatechin-3-O-gallate, ECg: epicatechin-3-O-gallate 
<smiles>[R]c1cc([C@H]2Oc3cc(O)cc(O)c3C[C@H]2O)cc(O)c1O</smiles>

1: $\mathrm{R}=\mathrm{OH}$

2: $\mathrm{R}=\mathrm{H}$<smiles>CC(O)CCC(O)Cc1ccc(O)c(O)c1</smiles>

7<smiles>Oc1cccc(O)c1O</smiles>

3

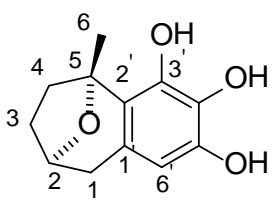

8<smiles>[R]c1cc(C[C@H](O)Cc2c(O)cc(O)cc2O)cc([R])c1O</smiles>

$$
\begin{aligned}
& \text { 4: } \mathrm{R}_{1}{ }^{\prime} \mathrm{R}_{2}=\mathrm{OH} \\
& \text { 5: } \mathrm{R}_{1}=\mathrm{H}^{\prime} \mathrm{R}_{2}=\mathrm{OH} \\
& \text { 6: } \mathrm{R}_{1}=\mathrm{R}_{2}=\mathrm{H}
\end{aligned}
$$

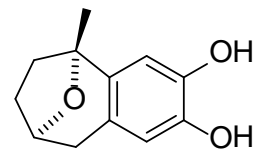

9

Fig. 2 Structures of compounds 1-9. 


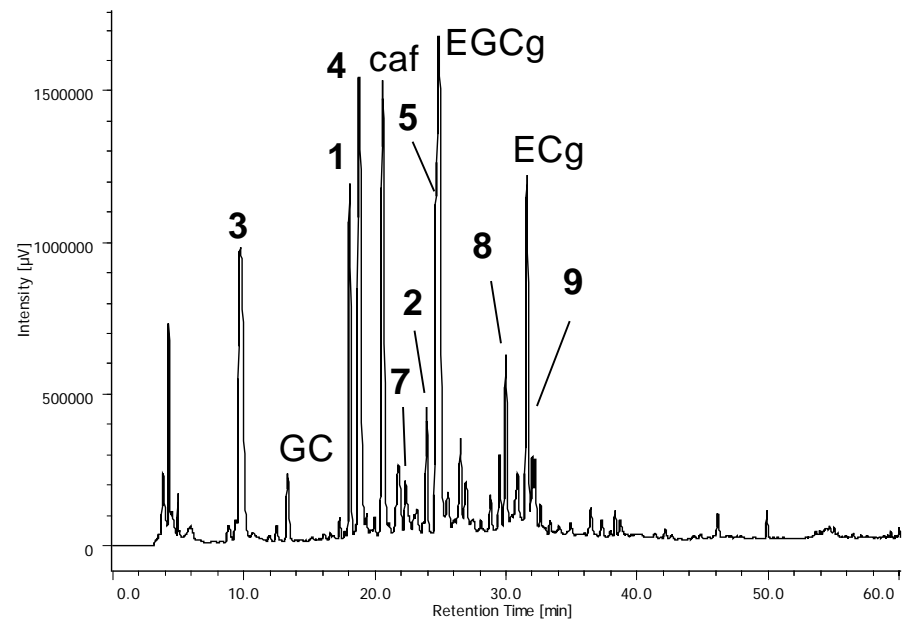

Fig. 3 HPLC (max absorbance) of mixed-fermentation product of green tea with lahpet-so (after 10 weeks). 

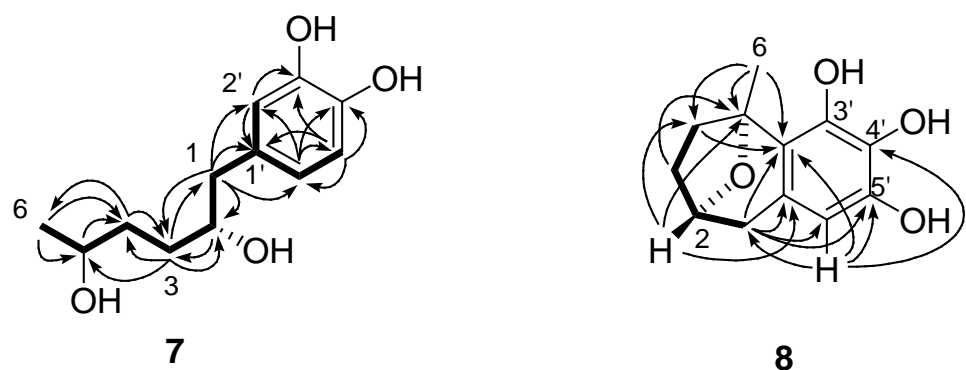

8

$-{ }^{1} \mathrm{H}-{ }^{1} \mathrm{H}$ COSY $\curvearrowright \mathrm{HMBC}$

Fig. $4{ }^{1} \mathrm{H}-{ }^{1} \mathrm{H}$ COSY and HMBC correlations for $\mathbf{7}$ and 8. 


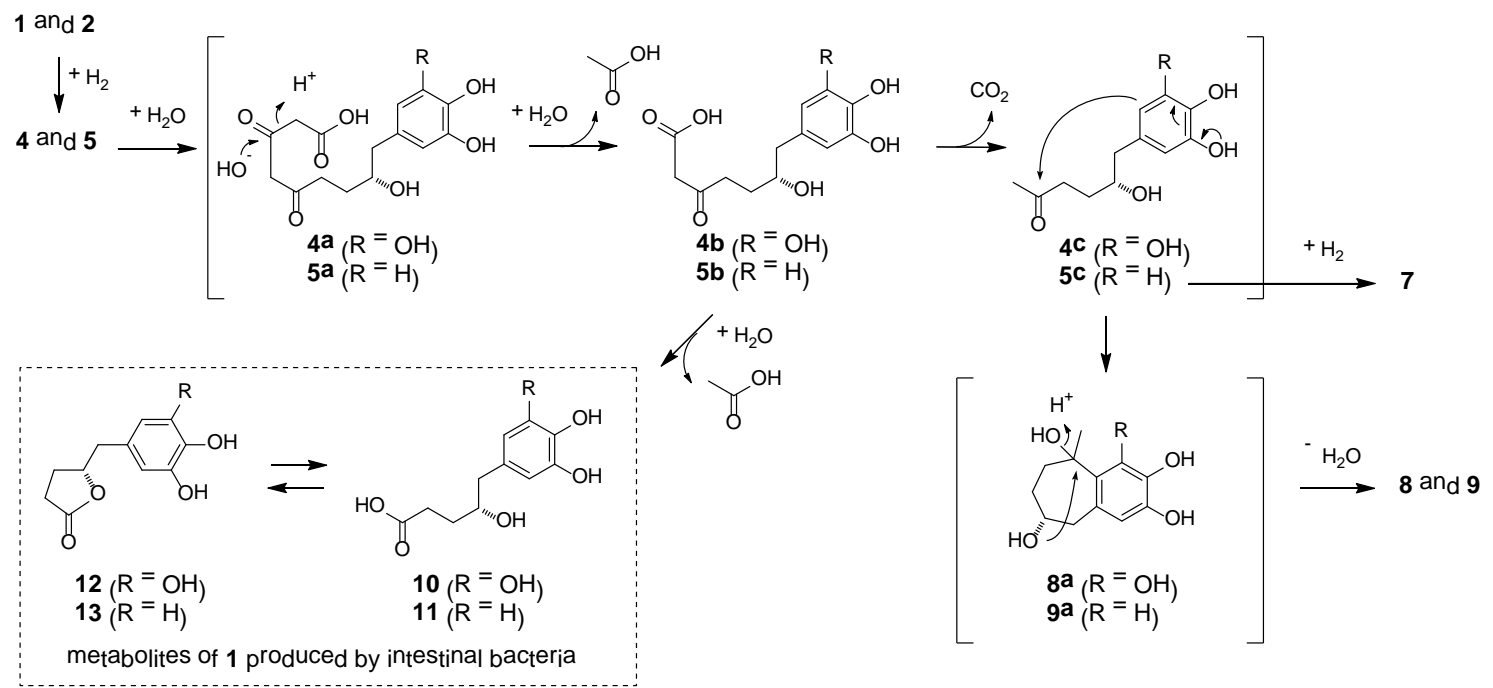

Fig. 5 Possible production mechanism of $\mathbf{7}$ and $\mathbf{8}$. 